\title{
Analysis of cocaine and nicotine metabolites in wastewater by liquid chromatography-tandem mass spectrometry. Cross abuse index patterns on a major community.
}

\author{
Álvaro Lopes ${ }^{a^{*}, e}$, Nuno Silva ${ }^{b}$, M. R. Bronze ${ }^{b, c, d}$, João Ferreira ${ }^{b}$, José Morais ${ }^{b}$ \\ a Laboratory of Toxicology, Faculty of Pharmacy, University of Lisbon, Av.Prof.Gama Pinto, 1649-003 Lisbon, Portugal \\ Pinto, 1649-003 Lisbon, Portugal \\ 'IBET, Instituto de Biologia Experimental e Tecnológica, Apartado 12, 2781-901 Oeiras, Portugal \\ d ITQB, Instituto de Tecnologia Química e Biológica, Universidade Nova de Lisboa, Avenida da República, Estação Agronómica \\ Nacional, 2780-157 Oeiras, Portugal. \\ e Instituto Superior de Ciências da Saúde Egas Moniz - Quinta da Granja - Monte de Caparica, 2829-511 Caparica, Portugal \\ *Corresponding author.Tel.: +351 217946400; fax: +351 217946470. \\ E-mail address: atlopes@ff.ul.pt (A. Lopes)

\section{HIGHLIGHTS} \\ Cross abuse index patterns on licit and illicit drugs by means of sewage assessment \\ $>$ Data about cocaine and nicotine consumption from a Portuguese population \\ $>$ Co-evaluation of cocaine abuse estimates based on local drug purity levels
}

${ }^{\mathrm{b}}$ iMed - Research Institute for Medicines and Pharmaceutical Sciences - Faculty of Pharmacy, University of Lisbon, Av. Prof. Gama

\begin{abstract}
A method based on sample preparation by solid phase extraction and analysis by liquid chromatography and mass spectrometry was validated and used for simultaneous analysis of cocaine, benzoylecgonine and cotinine in samples collected at the major wastewater treatment plant in the city of Lisbon. The aim was to estimate the consumption of both cocaine and nicotine in this community and establish an index involving both drugs supported by the relevance of nicotine as a significant anthropogenic marker. The study was made on two different week days during a month in order to evaluate patterns of consumption outside weekends. Cocaine and nicotine ingestion levels were backcalculated and expressed as mass of pure drugs consumed per day and per 1000 inhabitants (mean: $0.604 \mathrm{~g}$ and $5.860 \mathrm{~g}$ respectively). Cocaine was also expressed on the basis of local drug purity levels (33.7\%) with a corresponding increase on dose assessments, and community drug abuse profiles. The authors sustain that this approach should always be included in drug studies of this kind allowing a better drug abuse assessment. No significant different patterns of consumption were obtained during the working days studied with the exception of one case coincident with a national holiday that showed an increased typical profile found on other non-working day studies, namely weekends. A fairly significant relationship was found between nicotine and cocaine consumption that should be further evaluated in future studies. Pharmacokinetic considerations were made and proposed for cocaine assessment based on the impact on back calculations after common simultaneous consumption of cocaine and ethanol.
\end{abstract}

\section{Keywords: Wastewater, Cocaine, Benzoylecgonine, Cotinine, Nicotine}

\section{Introduction}

The analysis of sewage drug biomarkers (SDBs) has recently been established as a complementary approach for monitoring patterns and trends of illicit drug use in communities (Banta-Green et al., 2009; Berset et al., 2010; Castiglioniet al., 2011; Irvine et al., 2011; Karolak et al., 2010; Metcalfe et al., 2010; Reid et al., 2011; Terzic et al., 2010; van Nuijs, et al., 2011a; van Nuijs et al., 2009a; Zuccato et al., 2008). In 2012 it has been published the first harmonized study involving drug wastewater analysis in 19 European cities (Thomas 2012). Moreover, in 2013, using data from this study, a critical review was made to integrally 
address the uncertainties associated with the estimations of community drug use through sewage analysis, proposing a set of best practices requirements (Castiglioni et al., 2013).

Cocaine $(\mathrm{COC})$ remains the second most commonly used illicit drug in Europe, although prevalence levels and trends differ considerably between countries (EMCDDA, 2012). In Portugal results from the II National Population Survey on Psychoactive Substances in the Portuguese Population (15-64 years of age), the latest national survey available dated from 2007, indicate that alcohol and tobacco are the licit substances preferably used by the Portuguese population, and cannabis, cocaine and ecstasy, the illicit substances with lifetime prevalence respectively of $11,7 \%, 1,9 \%$ and $1,3 \%($ IDT, 2011). The prevalence of cocaine use in the last 30 days/12 months has increased from 0.1/0.3 (year 2001) to 0.3/0.6 (year 2007), which was a strong incentive for selecting cocaine as the drug of choice for this sewage study in the capital of Portugal, analyzing the influents of the main wastewater treatment plant (WWTP) in the city of Lisbon, Alcântara (Fig.1).

The aims of this work were (1) to assess the consumption of both cocaine and nicotine through the quantification of cocaine $(\mathrm{COC})$, benzoylecgonine $(\mathrm{BE})$ and cotinine $(\mathrm{CT})$ in the influents of a major urban wastewater treatment plant, by the means of an implemented and validated liquid chromatography-tandem mass spectrometry (LC-MS/MS) analytical method; (2) to establish a relationship index between tobacco and cocaine consumption and (3) to propose a complementary data evaluation for better qualification of epidemiological studies by converting the number of cocaine doses adjusted to the average local purity levels of cocaine. This approach will produce a more realistic view on the extent of drug consumption and trafficking and is proposed as another index to be included on every sewage drug studies

\section{Material and methods}

\subsection{Reagents and materials}

LC-MS grade acetonitrile (ACN) and methanol (MeOH) were obtained from Scharlau ${ }^{\circledR}$ (Sharlau S.L., Sentmanat, Spain). Analytical grade $37 \%$ hydrochloric acid $(\mathrm{HCl})$, ammonium hydroxide $\left(\mathrm{NH}_{4} \mathrm{OH}\right)$ and ammonium acetate $\left(\mathrm{CH}_{3} \mathrm{COONH}\right)_{4}$ were purchased from Merck (Darmstadt, Germany) and VWR (Lisbon, Portugal). Ultra-pure water (18.2 M $\Omega . c m)$ was obtained from a Millipore-Direct Q3 UV system (Millipore ${ }^{\circledR}$, Bedford, MA, USA).Individual methanolic or acetonitrile solutions $(1 \mathrm{mg} / \mathrm{mL})$ of cocaine $(\mathrm{COC})$, benzoylecgonine $(B E)$, cotinine (CT) and their deuterated analogues $\left(C O C-d_{3}, B E-d_{3}, C T-d_{3}\right)$, were of analytical grade (purity > 98\%) and were purchased from Cerilliant (Round Rock, TX, USA). 
Oasis HLB (500 mg, $6 \mathrm{~mL}$ ) SPE cartridges were acquired from Waters (Barcelona, Spain) and a Waters Sep-Pak solid-phase extraction (SPE) Vacuum Manifold with 12 ports and dry vacuum system was also used in the SPE procedure.

\subsection{Sample site and sample collection}

Influent samples were collected from the main wastewater treatment plant (Alcântara-ETAR) in the region of Lisbon, Portugal. Samples were collected twice a week (Tuesday and Thursday) during four weeks, between the months of October and November 2011. Wastewater treatment plant (WWTP) samples were 24-h composite samples starting at midnight, collected on a time proportional sampling mode (120 minutes) and kept refrigerated during that process. The Alcântara WWTP serves the west part (A) and the center (A1) of the city of Lisbon (Fig.1) and two major suburban areas - Amadora and Oeiras. The WWTP is dimensioned to an estimate design capacity of 756.000 inhabitants with a flow processing capability of $6.6 \mathrm{~m}^{3} / \mathrm{s}$. This system has started functioning in 1989 with a primary treatment and chlorine disinfection. Since October 2009 several major benefits have been introduced including biological treatment and ultraviolet irradiation allowing possible reuse of outflows both internal and external. During the study the total volume treated by the WWTP reached on average $123000 \mathrm{~m}^{3} / \mathrm{day}$.

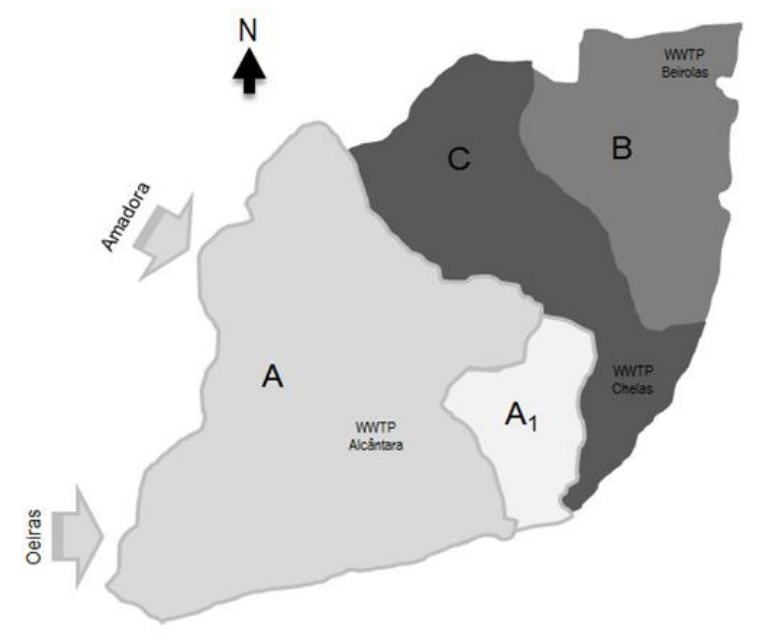

Fig.1- Lisbon WWTP's covering areas: A,A1-Alcântara (study); B-Beirolas; C-Chelas

\section{Sample preparation}

All $24 \mathrm{~h}$ WWTP samples were transferred into $1 \mathrm{~L}$ polyethylene bottles, adjusted to $\mathrm{pH}=2$ with $37 \% \mathrm{HCl}$ and stored at $-20{ }^{\circ} \mathrm{C}$ until analysis. These conditions have been described as granting negligible degradation of the cocaine and metabolites (Gheorghe et al., 2008) and cotinine (Chen et al., 2012). Concentrations of COD, BOD, phosphorus and azote were measured by the Alcântara WWTP laboratory. 
Samples were prepared according to previous published work (Gheorghe et al., 2008). Briefly $500 \mathrm{~mL}$ aliquots were defrosted and adjusted to $\mathrm{pH}=6$ with diluted ammonia followed by centrifugation $\left(4^{\circ} \mathrm{C}, 3800 \mathrm{rpm}, 10 \mathrm{~min}\right)$ using a refrigerated centrifuge Hermle Z-360K (Hermle Labortechnik, Wehingen, Germany) and filtering through Millipore $0.45 \mu$ m glass microfiber filter. A volume of $100 \mathrm{~mL}$ of each sample was then spiked with deuterated internal standards (IS) (20 ng of COC-d 3 , 50 ng of BE- $d_{3}$ and 50 ng of CT- $\left.\mathrm{d}_{3}\right)$. Oasis HLB (6 mL, $500 \mathrm{mg}$ ) solid-phase extraction (SPE) columns were used to clean-up and concentrate the samples. The SPE columns were previously conditioned with $3 \mathrm{~mL}$ of methanol followed by $3 \mathrm{~mL}$ of Milli-Q water. After sample elution at $3 \mathrm{~mL} / \mathrm{min}$ constant flow, SPE columns were washed with $3 \mathrm{~mL}$ of a $5 \% \mathrm{MeOH}$ solution, dried under vacuum for $15 \mathrm{~min}$ and finally eluted with $2 \times 4 \mathrm{~mL}$ of $\mathrm{MeOH}$. Eluted solutions were then dried under $\mathrm{N}_{2}$ atmosphere and re-dissolved with $1000 \mu \mathrm{L}$ of ACN. Samples were extracted in duplicate.

\subsection{Standard solutions and calibration}

Individual working standard solutions $(10 \mu \mathrm{g} / \mathrm{mL})$ were prepared by dilution in acetonitrile from initial stock standard solutions. These standards were stored at $-20^{\circ} \mathrm{C}$ in amber glass vial and brought to room temperature before use.

Calibration standard solutions were prepared in acetonitrile from working standard solutions of $10 \mu \mathrm{g} / \mathrm{mL}$. The concentration range of the solutions was from 0.1 to $100 \mathrm{ng} / \mathrm{mL}$. To all calibration solutions ( $1 \mathrm{~mL}$ ) the same amount of internal standards (IS) was added: $20 \mathrm{ng}$ of COC- $\mathrm{d}_{3}, 50 \mathrm{ng}$ of BE-d3 and $50 \mathrm{ng}$ of CT- $\mathrm{d}_{3}$.

\subsection{LC-MS/MS conditions}

LC analyses were performed using a Waters Alliance 2695 (Waters ${ }^{\circledR}$, Ireland) system equipped with a quaternary pump, automatic injector and a thermostated column compartment. The system was coupled to a Photodiode Array Detector Waters 996 PDA (Waters ${ }^{\circledR}$, Ireland) and a triple quadrupole mass spectrometer MicroMass Quattromicro ${ }^{\circledR}$ API (Waters ${ }^{\circledR}$, Ireland) equipped with an electrospray ionization source (ESI). For analysis, a volume of $5 \mu \mathrm{L}$ was injected. Chromatographic separations were performed using a Phenomenex ${ }^{\circledR}$ Luna $5 \mu \mathrm{m}$ HILIC $200 \mathrm{~A}(150 \times 3.00 \mathrm{~mm})$ column operating at $35{ }^{\circ} \mathrm{C}$ and the autosampler was at $10^{\circ} \mathrm{C}$. A mobile phase consisting of ammonium acetate $5 \mathrm{mM}$ (eluent A) and acetonitrile (eluent B) was used at a flow rate of $0.30 \mathrm{~mL} / \mathrm{min}$. The gradient elution profile was as follows: $0-0.5 \mathrm{~min}: 97 \%$ of eluent $\mathrm{B} ; 0.5-4.0 \mathrm{~min}: 97.0-55.0 \% \mathrm{~B} ;-4.0-6.5$ $\min : 55-50 \%$ B; $6.5-7.5 \mathrm{~min}: 50 \%$ B; $7.5-8.0 \mathrm{~min}: 50-97 \%$ B; 8.0-14.0 $\mathrm{min}$ : $97 \%$ B in order to equilibrate the column.

Conditions of analysis by MS/MS were optimised by infusion of individual working standard solutions of each compound in the ion source of the mass spectrometer, using a syringe pump at a flow rate of $20 \mu \mathrm{l} / \mathrm{min}$. The ESI source was used in positive 
ionization mode. The source temperature was at $120^{\circ} \mathrm{C}$; desolvation temperature $350{ }^{\circ} \mathrm{C}$, the cone gas flow was $50 \mathrm{~L} / \mathrm{h}$ and desolvation gas flow $750 \mathrm{~L} / \mathrm{h}$. The data acquisition was performed using Selected Reaction Monitoring mode (SRM) with a dwell time of $0.2 \mathrm{~s}$ in order to increase the sensitivity and selectivity of the analytical method. The operating conditions for the cone voltage (range from 10-40 V) and collision energy (range from 5-40 eV) were optimised in order to obtain the precursor ion of each target analyte and two product ions. One product ion was used for quantification (SRM1) and the other for qualification (SRM2) purposes. The final conditions used are presented in Table S1 and are according to conditions previously described (van Nuijs et al., 2009b; Srinivasan et al., 2000). MassLynx software (version 4.1) and QuanLynx (version 4.1) were used for controlling the equipment and also for data acquisition and processing.

\subsection{Method validation}

The validation was performed in accordance with the International Conference on Harmonisation (ICH) guidelines (ICH, 2005) with minor modifications. Briefly, the specificity, stability, linearity, concentration range, precision (intra-day and inter-day precision), accuracy, instrumental limit of detection (ILOD), instrumental limit of quantification (ILOQ) and method limit of quantification (MLOQ) (ISO, 1990; RELACRE, 2000; EC, 2002) were determined (Tables S2 and S3). Criteria requirements were based on Commission Decision 2002/657/EC (EC, 2002). To confirm linearity of the method, the Mandel Test was used according to ISO 8466-1:1990, residuals were calculated and the Rikilt test was performed (Van Trijp and Roos, 1991). Detailed method validation information is presented in Supporting Information.

\subsection{Sewage back calculations}

\subsubsection{Cocaine}

Refined cocaine, in the form of the base or hydrochloride salt, is self-administered mainly by snorting, smoking, genital application, and by injection. Cocaine is rapidly absorbed from mucous membrane and pulmonary vasculature depending on the blood rate appearance by the route of administration. After being absorbed, the substance distributes rapidly, mainly into the brain, spleen, kidney and lung where higher concentrations are reached (Bortolotti et al., 2012; Jeffcoat et al,1989) on their mass balance study with an intravenous administration of radiolabeled cocaine, have determined that less than $1 \%$ of the dose is excreted in the unchanged form ( $f_{e}$ coc), while a mean of $2.8 \%$ (range $2-3 \%$ ) of the dose is metabolized into ecgonine, $19.3 \%$ (range 18-22\%) into ecgonine methyl ester and 36.0\% (range $26-39 \%)\left(f_{m}\right.$ coc-BE) into benzoylecgonine (BE) (Jeffcoat et al., 1989). The authors also determined a fraction excreted of $10.8 \%$ of unidentified metabolites in urine, to which the later described metabolites can account for, namely $\mathrm{p}$ - and $\mathrm{m}$-hydroxycocaine, $\mathrm{p}$ - and $\mathrm{m}$-hydroxybenzoylecgonine, norcocaine, $\mathrm{N}$ - 
hydroxynorcocaine, norcocaine nitroxide and norcocaine nitrosonium ion (Kolbrich et al., 2006). 5.5\% of COC dose was also determined to be excreted in feces. The value of $36.0 \%$ for BE formation is similar to the average value of $38 \%$ suggested by Thomas et al. (2012), after revising pharmacokinetic studies available in the literature. The average elimination half-life of COC is reported to be 244 minutes after intravenous administration, 272 minutes after smoked administration and 299 minutes after intranasal administration (Bortolotti et al., 2012).

Similar fractions values were also obtained in another work (Cone et al., 1998) after an administration of an intravenous dose of cocaine, with means of $1.0 \%$ (range 0.15 to $2.97 \%$ ) and $39.2 \%$ (range 28.4 to $50.7 \%$ ), respectively for $f_{e} \operatorname{coc}$ and $f_{m}$ coc-BE.

However, coadministration of cocaine with alcoholic beverages alters the biotransformation pattern of COC, leading by transesterification in the liver to the formation of an equipotent metabolite cocaethylene ( $17 \%$ of COC dose) and decreasing $\mathrm{BE}$ formation due to the inhibition of the ethylesterase hydrolysis by ethanol (Harris et al., 2003). Based on these authors work, it is possible to calculate a metabolized fraction of COC into BE of approximately $24 \%$ of COC dose, after intravenous administration of $0.3,0.6$ or $1.2 \mathrm{mg} / \mathrm{kg}$ of radiolabeled cocaine together with ethanol $(1 \mathrm{~g} / \mathrm{kg})$, and considering the mean body weight of studied population $(71 \mathrm{~kg})$. Moreover, in the same study, the fraction excreted of unchanged COC is of approximately $5 \%$ for all administered doses, representing an increase of this fraction value when compared to COC administration without alcohol (less than 1\%). However both values are in the range of the described 1-9\% (Baselt, 2008).

More recently in a critical review article (Castiglioni et al., 2013), the authors propose for $\mathrm{f}_{\mathrm{m} \text { coc-BE }}$ a general value of $29 \%$ (RSD $26 \%)$, calculated based on human urinary excretion of BE collected from 20 published studies (total of 106 subjects), performed with cocaine administered by different routes. In the calculations the authors weighted not only the number of subjects by study, but also the frequency of $\mathrm{COC}$ use by the different routes of administration, based on data from a multicenter European study (Prinzleve et al., 2004).

Coadministration of alcohol and cocaine is common, with $50-90 \%$ of cocaine users reporting the ingestion of ethanol simultaneously in order to prolong the "high" and to minimize the dysphoric feelings associated with the use of cocaine (Goldstein et al., 2009). 
To estimate cocaine consumptions, back calculations were centered on previous published works (Zuccato et al., 2005; van Nuijs et al., 2011b) and were based on both the concentrations of cocaine and its major metabolite benzoylecgonine, which is present in wastewater at relatively high concentrations and is quite stable in water (Gheorghe et al., 2008).

From the concentrations of benzoylecgonine $(\mathrm{ng} / \mathrm{L})$ and with the flow rate (L/day) of the wastewater stream, BE loads ( $\mathrm{g} / \mathrm{day}$ ) can be calculated (Table 1). In order to compare the COC consumption results obtained in this study with other 19 European cities, these loads were then further back converted into consumed COC amount (COCeq) (g/day) (Table 2) using the molecular mass ratio of cocaine to benzoylecgonine (1.05) and assuming an average metabolized fraction of COC into BE ( $f_{m}$ cOC-BE) of $38 \%$ (back-correction factor of 2.76) as suggested by Thomas et al., 2012. However, it is believed that this average value does not take into account the simultaneous administration of cocaine with alcohol, an event likely to happen (EMCDDA, 2009), which reduces $B E$ formation.

Furthermore, in this work unmodified COC was also quantified (ng/L) in the samples (COCww), from which COCww load (g/day) was calculated (Table 1) and then back converted into consumed COC amount (COCww eq) (g/day) (Table 2), using as fraction excreted of unmodified $\operatorname{COC}\left(f_{e} \operatorname{coc}\right)$ the initial value of $1 \%$, described for COC consumption without alcohol.

Recently (van Nuijs et al., 2012) has assessed sewage degradation of BE and COCww in influent wastewater during $26 \mathrm{~h}$, at relevant conditions $\left(20^{\circ} \mathrm{C}\right.$ and $\left.\mathrm{pH} 7.5\right)$ concluding a modest formation of $\mathrm{BE}(0.2 \%$ per hour) on a linear pattern and $40 \%$ degradation of COCww after $12 \mathrm{~h}$ (quadratic decrease). Having in mind the impact that the use of the degradation factors might have on the final calculations, initial COCww concentration was also tested for correction by the use of a degradation factor of 43\% obtained through equation (1) described by van Nuijs et al. (2012) and using $24 \mathrm{~h}$ as time delay between excretion and sample collection. For $\mathrm{BE}$, the impact on the use of a formation correction factor was considered negligible.

Equation 1

$$
Y=0.1 X^{2}-4.6 X+97.2\left(\mathrm{R}^{2}=0.917\right)
$$

Analysis of COCww and BE concentration results (Table 1 ) showed a parallel pattern between them, so that, additionally with an observed closeness of COCww concentration values among all samples analyzed, it suggests non deliberate unused drug waste disposal. According to this assumption, for each sample the same value should be obtained for consumed COC (COCww eq and COCeq), back-calculated from COCww and BE concentrations by the use of wastewater flow and, respectively, the

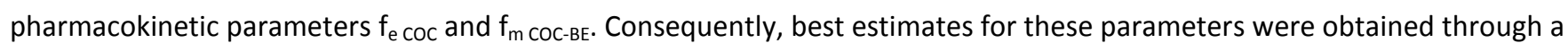
Microsoft Excel solver algorithm (Table 3) for each sample, forcing the ratio COCww eq / COCeq to unity and constraining $\mathrm{f}_{\mathrm{e}}$ coc 
to be less than or equal to $9.00 \%$ and $f_{m \text { COC-BE }}$ to be higher than or equal to $24.0 \%$. The ratio COCww eq / COCeq was computed according to equation (2).

\section{Equation 2}

$$
\frac{{ }^{C O C_{w w}}}{{ } O C_{e q}}=\frac{C O C_{w w} \cdot f_{m_{C O C-B E}}}{B E \cdot 1.05 \cdot f_{e_{C O C}}}
$$

For uncorrected stability/degradation COCww concentration values, the values of $8.36 \%$ and $24.2 \%$ were obtained as means of

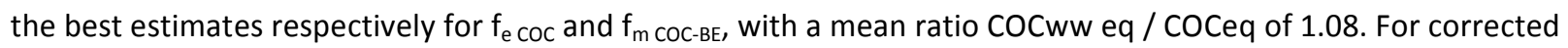
stability/degradation COCww concentration values (equation 1), best estimates were the limits of constraints, with a mean ratio COCww eq / COCeq of 2.32 that plainly deviates from the initial assumption and therefore COCww correction was discarded.

Thus, the best estimates obtained support the assumption of cocaine coadministration with alcohol and for this reason it was decided also to use in our calculations $9 \%$ as $f_{e}$ coc value and $24 \%$ as $f_{m}$ coc-BE value, the last one in agreement with the backcorrection factor of 3.0 that has been proposed by another author (van Nuijs, et al., 2011b).

The parameters BOD and COD were determined in all samples and used for population assessment. Moreover concentration levels for phosphorus and azote have also been determined for some samples. The number of inhabitants (Table 1$)$ is the mean of population determinations based on available parameters data for each sample.

\subsubsection{Nicotine}

Nicotine derivatives have also been proposed as possible chemical anthropogenic markers for domestic wastewater (Buerge et al., 2008) considering that nicotine, as a constituent of tobacco, is regularly consumed by a large fraction of the world's population. Approximately 5.5-6 trillion cigarettes are produced globally each year by the tobacco industry (WHO, 2002; Eriksen et al., 2012). Considering a typical nicotine content of $0.8 \mathrm{mg} /$ cigarette (Gorrod J, 1993), the annual global consumption of nicotine can be estimated at $5 \times 104$ tons. Nicotine would thus rank as a high production volume chemical. We will add to this an important constant outflow as it is widely accepted that most tobacco users strictly maintain daily levels of blood concentration of nicotine, adjusting the number of cigarettes or inhaling frequency. (Ashton and Watson, 1970; Murray et al., 1978; Kolonen et al., 1991; Nakazawa et al., 2004). 
Nicotine is distilled from burning tobacco and is carried proximally on inhaled tar droplets, reaching alveolar tissue from which about $80-90 \%$ is rapidly absorbed. Consumed nicotine is then extensively metabolized by oxidative enzymatic transformations mainly into primary metabolites cotinine (70-80\%) and nicotine $\mathrm{N}^{\prime}$-oxide (4-7\%). Cotinine (CT) is afterwards further metabolized into several sub-metabolites, making that only $10-15 \%$ of consumed nicotine is excreted as cotinine. Cotinine has been used as an indicator of tobacco exposure (Haufroid et al., 1998) and will be evaluated as such in this study. Nicotine itself was not investigated as this compound may enter into WW influents through cigarette stubs disposal. Typical concentrations of cotinine in a smoker's urine amount have been estimated to be around $1.6 \mathrm{mg} / \mathrm{L}$ (Umweltbundesamt, Dessau-Rosslau, 1998). Assuming a mean urine production of $1.5 \mathrm{~L} / \mathrm{day}$, the daily cotinine excretion of a smoker can be estimated at about $2.4 \mathrm{mg} / \mathrm{person} / \mathrm{day}$

(Buerge et al., 2008).

Cotinine concentration $(\mathrm{ng} / \mathrm{mL}$ ) values obtained for each sample were first corrected based on the work of Chang Chen et al. (2012) that suggest an increase fraction of CT initial concentration on samples kept at $20^{\circ} \mathrm{C}$ according to the linear equation $0.45^{*} \mathrm{t}$, where t represents the time delay between excretion and sample collection, assumed to be $24 \mathrm{~h}$ in our case. Initial CT concentration is increased by the breakdown of excreted cotinine-glucuronide conjugates, which represents a fraction of $12-$ $17 \%$ of consumed nicotine excreted in this conjugated form (Hukkanen et al., 2005; Benowitz et al., 1994). Results are presented in Table 1.

Table 1

Cocaine and cotinine quantitative data

\begin{tabular}{|c|c|c|c|c|c|c|c|c|c|c|c|c|}
\hline Date & $\begin{array}{l}\text { Population } \\
\text { (RSD\%) }\end{array}$ & $\begin{array}{c}\text { Flow } \\
\left(\mathrm{m}^{3} / \text { day }\right)\end{array}$ & $\begin{array}{c}\mathrm{BE} \\
\text { (ng/L) } \\
(\mathrm{RSD} \%)\end{array}$ & $\begin{array}{c}\mathrm{COCww} \\
\text { (ng/L) } \\
\text { (RSD\%) }\end{array}$ & $\begin{array}{l}\text { Load BE } \\
\text { (g/day) }\end{array}$ & $\begin{array}{l}\text { Load CoCwwe } \\
\qquad(\mathrm{g} / \text { day })\end{array}$ & $\begin{array}{c}\text { Initial CT } \\
\text { (ng/L) } \\
\text { (RSD\%5) }\end{array}$ & $\begin{array}{c}\text { Corrected CT } \\
\text { (ng/L) }\end{array}$ & $\begin{array}{l}\text { Load CT } \\
\text { (g/day) }\end{array}$ & $\begin{array}{l}\text { Consumed } \\
\text { NICOT } \\
\text { (g/day) }\end{array}$ & $\begin{array}{c}\text { Inhaled } \\
\text { NICOT } \\
\text { (g/day) }\end{array}$ & $\begin{array}{c}\text { Inhaled NICOT } \\
\text { (g/day/1000 } \\
\text { inh) }\end{array}$ \\
\hline 11-Oct (Tue) & $\begin{array}{c}515613^{\circ} \\
(15.3)\end{array}$ & 125120 & $\begin{array}{c}529 \\
(2.28)\end{array}$ & $\begin{array}{c}197 \\
(9.83)\end{array}$ & 66.2 & 24.6 & $\begin{array}{c}3493 \\
(2.27)\end{array}$ & 3153 & 394 & 2576 & 3030 & 5.8 \\
\hline 13-Oct (Thu) & $\begin{array}{c}346370^{c} \\
(39.2)\end{array}$ & 123100 & $\begin{array}{c}453 \\
(2.30)\end{array}$ & $\begin{array}{c}178 \\
(3.85)\end{array}$ & 55.8 & 21.9 & * & - & - & - & - & - \\
\hline 18-Oct (Tue) & $\begin{array}{c}405017^{\circ} \\
(15.0)\end{array}$ & 126680 & $\begin{array}{c}340 \\
(0.96)\end{array}$ & $\begin{array}{c}124 \\
(4.86)\end{array}$ & 43.1 & 15.7 & $\begin{array}{l}2522 \\
(4.55)\end{array}$ & 2277 & 288 & 1883 & 2215 & 5.3 \\
\hline 20-Oct (Thu) & $\begin{array}{c}468257^{c} \\
(5.1)\end{array}$ & 126770 & $\begin{array}{c}567 \\
(0.31)\end{array}$ & $\begin{array}{c}160 \\
(7.29)\end{array}$ & 71.9 & 20.3 & $\begin{array}{l}3504 \\
(6.41)\end{array}$ & 3163 & 401 & 2618 & 3080 & 6.6 \\
\hline 01-Nov (Tue) & $\begin{array}{c}234102^{b} \\
(15.7)\end{array}$ & 134780 & $\begin{array}{c}527 \\
(3.35)\end{array}$ & $\begin{array}{c}180 \\
(2.28)\end{array}$ & 71.0 & 24.3 & $\begin{array}{c}3075 \\
(10.14)\end{array}$ & 2775 & 374 & 2442 & 2873 & 12.9 \\
\hline 03-Nov (Thu) & $\begin{array}{c}358267^{c} \\
(9.2)\end{array}$ & 222030 & $\begin{array}{c}203 \\
(1.53)\end{array}$ & $\begin{array}{c}90 \\
(4.07)\end{array}$ & 45.1 & 20.0 & $\begin{array}{l}1129 \\
(4.71)\end{array}$ & 1019 & 226 & 1477 & 1737 & 4.9 \\
\hline 10-Nov (Thu) & $\begin{array}{c}332271^{\mathrm{c}} \\
(11.9)\end{array}$ & 177090 & $\begin{array}{c}292 \\
(1.98)\end{array}$ & $\begin{array}{c}162 \\
(9.31)\end{array}$ & 51.7 & 28.7 & $\begin{array}{l}1833 \\
(1.81)\end{array}$ & 1654 & 293 & 1913 & 2251 & 6.8 \\
\hline Mean & 379986 & 147940 & 416 & 156 & 57.8 & 22.2 & 2593 & 2340 & 329 & 2151 & 2531 & 5.9 \\
\hline
\end{tabular}

Notes: * Lost in process; "Population mean value based on BOD, COD, $\mathrm{N}$ and P levels; "Population mean value based on BOD, COD and $\mathrm{N}$ levels; 'Population mean value based on BOD and COD levels $\mathrm{BE}$ (benzoylecgonine concentration in wastewater); $\mathrm{COCww}$ (cocaine concentration in wastewater); ${ }^{\circ} \mathrm{Calculated}$ as $\mathrm{BE}(\mathrm{ng} / \mathrm{L}) \times \mathrm{Flow}\left(\mathrm{m}^{3} / \mathrm{day}\right) \times 10^{-5} ;{ }^{\mathrm{e}} \mathrm{Calculated}$ as $\mathrm{COCww}(\mathrm{ng} / \mathrm{L}) \times \mathrm{Flow}\left(\mathrm{m}^{3} / \mathrm{day}\right) \times 10^{-6}$ : RSD\% represents sample's total variability (duplicate extraction and triplicate injections);: RSD\% represents sample's total variability (duplicate extraction and duplicate injections) 
Table 2

Cocaine quantitative data

\begin{tabular}{|c|c|c|c|c|c|c|c|c|c|}
\hline Date & $\begin{array}{l}\text { COCeq }^{a} \\
\text { (g/day) }\end{array}$ & $\begin{array}{l}\text { COCeq }^{b} \\
\text { (g/day) }\end{array}$ & $\begin{array}{c}\text { COCww eq } \\
\text { (g/day) }\end{array}$ & $\begin{array}{c}\text { COCww eq }^{\mathrm{d}} \\
\text { (g/day) }\end{array}$ & $\begin{array}{c}\text { COCeq }^{e} \\
(\mathrm{mg} / \text { day/1000 inh) }\end{array}$ & $\begin{array}{c}\text { COCeq }^{\dagger} \\
(\mathrm{mg} / \text { day } / 1000 \mathrm{inh})\end{array}$ & $\begin{array}{c}\mathrm{COC}_{\text {Doses }}^{\mathrm{g}} \\
\text { Pure doses / day }\end{array}$ & $\begin{array}{c}\text { COC }_{\text {Doses }}{ }^{h} \\
\text { "st" doses / day }\end{array}$ & $\begin{array}{c}\text { COC }_{\text {Doses }} \\
\text { "st" doses / day / } 1000 \mathrm{inh}\end{array}$ \\
\hline 11-Oct & 182.5 & 289.0 & 2464.8 & 273.9 & 353.9 & 560.4 & 2890 & 8574 & 17 \\
\hline 13-Oct & 153.8 & 243.4 & 2191.1 & 243.5 & 443.9 & 702.8 & 2434 & 7224 & 21 \\
\hline 18-Oct & 118.8 & 188.0 & 1570.9 & 174.5 & 293.2 & 464.3 & 1880 & 5580 & 14 \\
\hline 20 -Oct & 198.2 & 313.8 & 2028.3 & 225.4 & 423.2 & 670.2 & 3138 & 9312 & 20 \\
\hline 01-Nov & 195.8 & 310.1 & 2426.1 & 269.6 & 836.6 & 1324.6 & 3101 & 9202 & 39 \\
\hline 03-Nov & 124.3 & 196.8 & 1998.3 & 222.0 & 346.9 & 549.2 & 1968 & 5839 & 16 \\
\hline 08-Nov & -- & -- & -- & -- & -- & -- & -- & -- & -- \\
\hline $10-\mathrm{Nov}$ & 142.6 & 225.7 & 2868.8 & 318.8 & 429.1 & 679.4 & 2257 & 6699 & 20 \\
\hline Mean & 159.4 & 252.4 & 2221.2 & 246.8 & $381.7^{i}$ & $604.4^{\prime}$ & 2524 & 7490 & $18^{i}$ \\
\hline
\end{tabular}

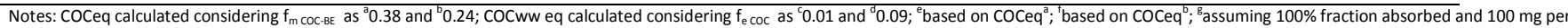
pure dose; "adjusted to local "street" purity of $33.7 \%$ (2011); 'mean value excluding $1^{\text {st }}$ November data

From the corrected concentrations of cotinine (CT) (ng/L) and with the flow rate (L/day) of the wastewater stream, CT loads (g/day) were calculated. These loads were then further back converted into consumed nicotine amount (g/day) using $14.1 \%$ as the fraction of consumed nicotine excreted as cotinine form, calculated from original data published by Benowitz (Benowitz et al., 1994) as well as the molecular mass ratio of nicotine to cotinine (0.92). For the calculation of inhaled nicotine, an absorbed fraction value of $85 \%$ was taken into account (Hukkanen et al., 2005). Results are presented in Table 1.

Table 3

Microsoft Excel Solver estimates

\begin{tabular}{cccc}
\hline Date & $\mathrm{f}_{\mathrm{m} \text { COC-BE }}$ & $\mathrm{f}_{\mathrm{e} \text { cOC }}$ & COCww eq / COCeq \\
\hline 11-Oct & 0.240 & 0.0853 & 1.00 \\
13-Oct & 0.240 & 0.0900 & 1.00 \\
18-Oct & 0.240 & 0.0835 & 1.00 \\
20-Oct & 0.248 & 0.0667 & 1.00 \\
01-Nov & 0.244 & 0.0797 & 1.00 \\
03-Nov & 0.240 & 0.0900 & 1.13 \\
10-Nov & 0.240 & 0.0900 & 1.41 \\
\hline Mean & 0.242 & 0.0836 & 1.08
\end{tabular}

Notes: ${ }^{a}$ Computed according to equation (2) based on uncorrected COCww and on the best estimates of $f_{m}$ COC-BE and $f_{e}$ COC for each sample

Table 4

Cocaine quantitative data (Adapted from Mathieu et al., 2011)

\begin{tabular}{|c|c|c|c|c|c|c|c|c|c|c|c|}
\hline Sample & $\begin{array}{c}\text { Flow } \\
\left(\mathrm{m}^{3} / \text { day }\right)\end{array}$ & $\begin{array}{c}\mathrm{BE} \\
(\mathrm{ng} / \mathrm{L})\end{array}$ & $\begin{array}{c}\text { COCww } \\
\text { (ng/L) }\end{array}$ & $\begin{array}{l}\text { Load BE } \\
\text { (g/day) }\end{array}$ & $\begin{array}{l}\text { Load COCww } \\
\text { (g/day) }\end{array}$ & $\begin{array}{l}\text { COCeq }^{a} \\
\text { (g/day) }\end{array}$ & $\begin{array}{l}\text { COCeq }^{b} \\
\text { (g/day) }\end{array}$ & $\begin{array}{c}\text { COCww eq }^{c} \\
\text { (g/day) }\end{array}$ & $\begin{array}{c}\text { COCww eq }^{d} \\
\text { (g/day) }\end{array}$ & $\begin{array}{c}\text { Ratio } \\
\text { coCww eq / coCeq }\end{array}$ & $\begin{array}{c}\text { Ratio } \\
\text { cocww eq }{ }^{d} / \text { coCeq }^{b}\end{array}$ \\
\hline A & 260247 & 280 & 114 & 73 & 30 & 201 & 318 & 2967 & 330 & 14.8 & 1.04 \\
\hline B & 141236 & 1788 & 1928 & 253 & 272 & 696 & 1103 & 27230 & 3026 & 39.1 & 2.74 \\
\hline $\mathrm{E}$ & 71885 & 1040 & 297 & 75 & 21 & 206 & 326 & 2135 & 237 & 10.4 & 0.73 \\
\hline $\mathrm{F}$ & 120263 & 350 & 124 & 42 & 15 & 116 & 184 & 1491 & 166 & 12.8 & 0.90 \\
\hline 1 & 57800 & 954 & 336 & 55 & 19 & 152 & 241 & 1942 & 216 & 12.8 & 0.90 \\
\hline K & 114800 & 694 & 322 & 80 & 37 & 220 & 348 & 3697 & 411 & 16.8 & 1.18 \\
\hline L & 77000 & 853 & 300 & 66 & 23 & 181 & 287 & 2310 & 257 & 12.8 & 0.90 \\
\hline $\mathrm{P}$ & 95900 & 774 & 311 & 74 & 30 & 205 & 324 & 2983 & 331 & 14.6 & 1.02 \\
\hline$Q$ & 180000 & 802 & 406 & 144 & 73 & 398 & 630 & 7308 & 812 & 18.4 & 1.29 \\
\hline \multirow[t]{2}{*}{ R } & 195000 & 2400 & 1000 & 468 & 195 & 1290 & 2043 & 19500 & 2167 & 15.1 & 1.06 \\
\hline & & & & & & & & & Mean & 16.7 & 1.18 \\
\hline
\end{tabular}




\subsubsection{Estimation of Population Size}

The assessment of population served by wastewater treatment plants remains one of the major subjects to be improved in order to reduce biases when producing back-calculations for estimating drug use per number of inhabitants. Several approaches have been suggested through the use of anthropogenic markers such as personal care products, pharmaceuticals used in chronic therapies, sweeteners, methadone, caffeine or the concentrations of P (Phosphorus), N (Azote), BOD (Biochemical Oxygen Demand) and COD (Chemical Oxygen Demand). These last parameters have been proposed on drug wastewater studies based on the previous knowledge that one inhabitant is equivalent to $1.7 \mathrm{~g} /$ day $\mathrm{P}, 12.5 \mathrm{~g} /$ day N, $59 \mathrm{~g} /$ day BOD and $128 \mathrm{~g} / \mathrm{day}$ COD (Van Nuijs, et al., 2011; Andreottola et al., 1994; Zessner et al., 2005; Garnier et al., 2006).

\section{Results and discussion}

The sampling process of the influents was made according to the WWTP-Alcântara collection protocol, on a time proportional schedule of 120 minutes. The uncertainty asssociated with the different models of sampling has been discussed by several authors (Ort, et al., 2010; Ort et al., 2010b; Castiglioni et al., 2013) regarding optimization of the collection step, being the flowproportional mode the method that should be adopted for best results, as it minimizes pulse drug flows. In our study, sample collection was made from a WWTP retention tank and short-term fluctuations of the studied substances should be largely attenuated by the mixing process in the tank and thus the error attributable to sampling frequency would be less critical as mentioned by some other authors (EMCDDA, 2008).

The validated method was successfully applied to the 8 wastewater samples collected in Alcântara WWTP (Lisbon). After extraction, each sample was analyzed in triplicate for the determination of COC and BE concentrations (ng/L) and in duplicate for CT. The results from one of the collected samples were disregarded and excluded as outliers after Grubbs test evaluation of load COCww data. One sample was lost in process during CT quantification. For each catchment day, population estimate's uncertainty based on BOD, COD, P and N parameters ranged from 5.1 to $39.2 \%$ (RSD) which is in agreement with data from the harmonized study performed in 19 European studies (Thomas et al., 2012), ranging between 7-55\% (Castiglioni et al., 2013). For all catchment days, excluding the $1^{\text {st }}$ November corresponding to a national holiday, the population estimates ranged between $380,000-400,000$. The day to day population estimate's uncertainty is similar with previous work (van Nuijs, Mougel, et al., 2011), where large variations in the amount of served inhabitants were also observed. 
For cocaine consumption analysis, in back calculations the values of $9 \%$ and $24 \%$, respectively for $f_{e}$ coc and $f_{m \text { coC-BE }}$ were used. These are likely to be the most realistic estimates for these pharmacokinetic parameters. In order to validate these estimates, COCww and BE concentration data (10 samples) published elsewhere (Mathieu et al., 2011) were used to back calculate COCww eq and COCeq for the same samples, obtained from four different Swiss cities (Table 4). Considering $f_{e} \operatorname{coc}$ and $f_{m}$ coc-BE respectively as $1 \%$ and $38 \%$, a mean value of 16.7 (range 10.4 to 39.1 ) is obtained for the ratio COCww eq / COC eq, while the use of $9 \%$ and $24 \%$ for the same pharmacokinetic parameters enables to obtain a more plausible mean value of 1.18 (range 0.73 to 2.74 ) for the same ratio.

Despite COCeq and COCww eq were calculated, cocaine consumption analysis back calculations based on BE loads are preferred due to a higher waste water stability of this metabolite when compared to COCww. Cocaine consumed amounts (COCeq) were also normalized to population and expressed per thousand inhabitants. Cocaine consumed doses $\left(\mathrm{COC}_{\text {Doses }}\right)$ are expressed as pure drug, assuming an absorbed fraction of $100 \%$ and $100 \mathrm{mg}$ per pure dose, and also expressed at "street" (st) purity level (Table 2). In the year of the study (2011) the purity of cocaine at street level in Portugal was 33.7\%, according to data provided by IDT (Institute on Drugs and Drug Addiction, Lisbon).

Based on back-calculations assuming cocaine co-administered with alcohol, the mean amount of consumed cocaine in this study was determined as 252 g/day (range 188 to 314 g/day), representing a daily consumption of 2524 "pure" doses (range 1880 to 3101 ) or 7490 "street" purity level doses (range 5580 to 9312 ).

When normalized to population, $\mathrm{COCeq}$ and $\mathrm{COC}_{\text {Doses }}$ show a high value for the sample collected on the $1^{\text {st }}$ of November (National holiday), not seen on absolute values, which might be justified by a "concentration" effect due to increase of cocaine consumption. This is a comparable pattern to common weekend consumption profiles found in other studies. Excluding $1^{\text {st }}$ of November data, mean value of consumed cocaine was determined as $604 \mathrm{mg} /$ day/1000 inhabitants, which represents a daily consumption of 18 "street" purity level doses per 1000 inhabitants. Assuming one dose per person, wastewater analysis suggests an estimate of the real abuse "street" cocaine consumption prevalence of $1.8 \%$, which, when compared to the prevalence of cocaine use in Portugal in the last 30 days/12 months $(0.3 / 0.6)$, according to the last available survey (IDT, 2011), represents a six fold or three fold increase, respectively for the 30 days or 12 months prevalence data. 
Based on back-calculations assuming cocaine administered without alcohol and excluding $1^{\text {st }}$ of November data, our work shows a daily mean estimate of Lisbon's consumption of $382 \mathrm{mg}$ per 1000 inhabitants (range 293 to $444 \mathrm{mg} / \mathrm{day} / 1000$ inhabitants). When compared with other 19 cities consumption published elsewhere (Thomas et al., 2012), Lisbon's daily consumption is lower than consumption observed in the cities of Milan, Santiago de Compostela, Paris and Brussels (ranging from 511 to 662 mg/day/1000 inhabitants), and higher than consumption observed in the cities of Budweis, Zagreb, Helsinki, Turku, Oslo, Stockholm, and Umeå (ranging from 2 to $146 \mathrm{mg} /$ day/1000 inhabitants). However, it should be emphasized that consumption data on these cities can be 1.58 times higher if it is assumed cocaine intake with alcohol.

Cotinine concentration in wastewater samples ranged from $1.13 \mu \mathrm{g} / \mathrm{L}$ to $3.50 \mu \mathrm{g} / \mathrm{L}$ (mean of $2.59 \mu \mathrm{g} / \mathrm{L}$ ), values considered to be similar to the estimates described for Zurich (2.65 $\mu \mathrm{g} / \mathrm{L}$ ) (Buerge et al., 2008) or Adelaide (Australia) (3.50 $\mu \mathrm{g} / \mathrm{L})$ (Chen et al., 2012). Based on back-calculations of corrected cotinine concentrations, our work enabled to quantify a mean estimate of inhaled nicotine of $2531 \mathrm{~g} /$ day (range 1737 to $3080 \mathrm{~g} / \mathrm{day}$ ). When normalized to population, a daily range of 4.85 to $12.9 \mathrm{~g} / 1000$ inhabitants is obtained. As for COCeq, population normalized inhaled nicotine showed a high value for the sample collected on the national holiday, not seen on absolute values, which might be justified by a probable increase of nicotine consumption. When excluding $1^{\text {st }}$ of November data, a daily mean estimate of $5.86 \mathrm{~g}$ per 1000 inhabitants is obtained. Assuming a mean of 0.8 $\mathrm{mg} /$ cigarette (Gorrod J, 1993), this value corresponds to an estimate of 732.5 cigarettes/day/100 inhabitants. In a European survey (EU, 2012) 44\% of the Portuguese interviewed claimed to smoke between 11 and 20 cigarettes per day. Therefore nicotine consumption estimate can be calculated in the range of 36.6 to $66.6 \%$ of consumers, which is in accordance to the above survey that mentions to Portugal an average of $23 \%$ of consumers with major contributors in the ages of $25-39$ years $(37 \%)$ and $15-24$ years (31\%).

Moreover, in order to assess cocaine consumption based on back calculations from BE concentration data and the recent proposed general value of $29 \%$ for $f_{m \text { coc-BE }}$ (Castiglioni et al., 2013), in our work the mean amount of consumed COC can be determined as 209 g/day (range (156 to 260 g/day), representing a daily consumption of 2089 "pure" doses (range 1556 to 2597 ) or 6198 "street" purity level doses (range 4618 to 7706$)$. When normalized to population, and excluding $1^{\text {st }}$ November data, the mean value of consumed COC can be determined as $500 \mathrm{mg} /$ day/1000 inhabitants.

A correlation between inhaled nicotine and COCeq was tested by the means of its absolute and population normalized values. Positive relationships were observed between these variables (Fig. 2 and Fig. 3), with $\mathrm{R}^{2}$ values of 0.854 and 0.980 and linear 
equations COCeq $(\mathrm{g} / \mathrm{day})=7.56+0.0973 \mathrm{x}$ inhaled nicotine $(\mathrm{g} / \mathrm{day})$ and COCeq $(\mathrm{g} / \mathrm{day} / 1000$ inhab) $=-0.0875+0.114 \mathrm{x}$ inhaled nicotine (g/day/1000 inhab) . Analysis of the regression results indicates that the slope parameters are significantly different from zero, with $\mathrm{p}$ values of 0.00842 and 0.000156 respectively for these equations. For both equations the $95 \%$ confidence interval for the intercept includes zero value. Regardless of the low number of samples used in this study, the linear relationship that seems to exist between cocaine and nicotine consumptions may characterize a certain pattern for the Lisbon population serving Alcântara WWTP but it should be further evaluated.

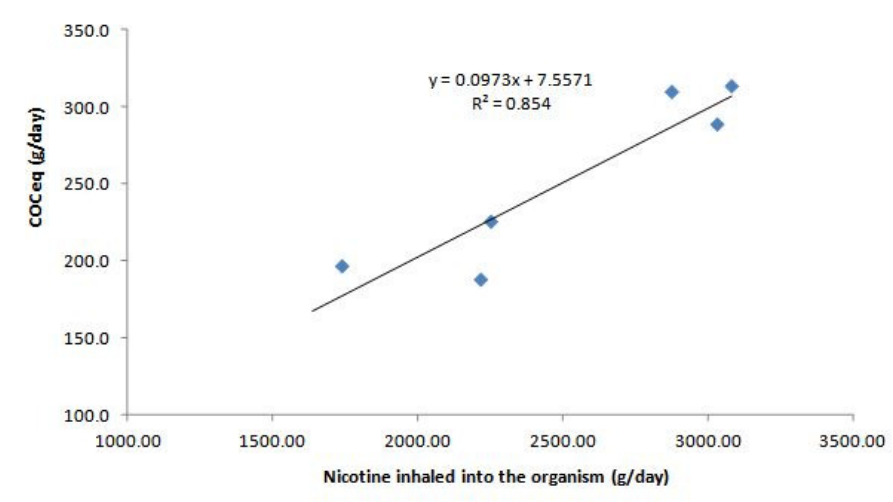

Fig.2 - Plot of consumed COC amount (COCeq) (g/day) vs inhaled nicotine into the organism (g/day).

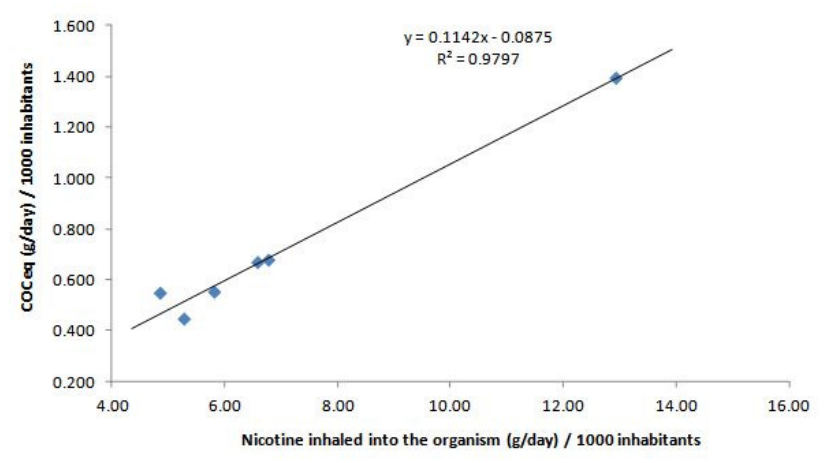

Fig.3 - Plot of consumed COC amount (COCeq) (g/day/1000 inhabitants) vs inhaled nicotine into the organism (g/day/1000 inhabitants)

\section{Conclusion}

The present project obtained the first sewage forensic estimates (SF/E) in Portugal and confirmed the great potentials of this epidemiological approach in drug abuse assessment. The obtained cocaine and benzoylecgonine concentration results enabled to optimize estimates for the pharmacokinetic parameters to be used on back calculations of cocaine consumption in the population serving the main Lisbon WWTP. Moreover, it is suggested for this community a possible cross abuse index pattern between cocaine and nicotine consumption that should be further evaluated. On a perspective of toxicological and 
environmental approach, apart from the levels of cocaine abuse, it is remarkable the toxic nicotine amounts involved on an urban daily base consumption.

\section{Acknowledgements}

This work was funded by REDE/1518/REM/2005 for the LC-MS/MS equipment and by funds from former Projecto Vida and

Ordem dos Farmacêuticos (Portuguese Pharmaceutical Society).

We wish to thank José Martins and Paulo Coelho from SIMTEJO-Alcântara Wastewater Treatment Plant (Lisbon) for the supply of wastewater samples and analytical control data; and João Goulão and Óscar Duarte from IDT (Institute on Drugs and Drug Addiction, I.P., Lisbon) for the supply of 2011 Portuguese cocaine purity data and Joana Santos from Lisbon Forensic Criminal Laboratory (LPC).

\section{References}

Ashton H, Watson D. Puffing frequency and nicotine intake in cigarette smokers. British Medical Journal 1970;3:679-81.

Banta-Green CJ, Field J a, Chiaia AC, Sudakin DL, Power L, de Montigny L. The spatial epidemiology of cocaine, methamphetamine and 3,4-methylenedioxymethamphetamine (MDMA) use: a demonstration using a population measure of community drug load derived from municipal wastewater. Addiction 2009;104:1874-80.

Baselt R. Disposition of toxic drugs and chemicals in man. 8th ed. Biomedical Publications. Foster City. California; 2008.

Benowitz L, Peyton J, Fong I, Gupta S. Nicotine Metabolic Profile in Man : Comparison of Cigarette Smoking and Transdermal Nicotine. The Journal of Pharmacology and Experimental Therapeutics 1994;268:296-303.

Berset J-D, Brenneisen R, Mathieu C. Analysis of llicit and illicit drugs in waste, surface and lake water samples using large volume direct injection high performance liquid chromatography--electrospray tandem mass spectrometry (HPLC-MS/MS). Chemosphere 2010;81:859-66.

Bortolotti F, Gottardo R, Pascali J, Tagliaro F. Toxicokinetics of Cocaine and Metabolites : The Forensic Toxicological Approach. Current Medicinal Chemistry 2012;19:5658-63.

Buerge IJ, Kahle M, Buser H-R, Müller MD, Poiger T. Nicotine derivatives in wastewater and surface waters: application as chemical markers for domestic wastewater. Environmental science \& technology 2008;42:6354-60.

Castiglioni S, Bijlsma L, Covaci A, Emke E, Hernández F, Reid M, et al. Evaluation of uncertainties associated with the determination of community drug use through the measurement of sewage drug biomarkers. Environmental Science \& Technology 2013;47:1452-60.

Castiglioni, Sara, Zuccato, E RF. Illicit Drugs in the Environment. Occurrence, Analysis, and Fate Using Mass Spectrometry. Ed. NJ John Wiley \& Sons: Hoboken. 2011. 
Chen C, Kostakis C, Irvine RJ, Felgate PD, White JM. Evaluation of pre-analysis loss of dependent drugs in wastewater: stability and binding assessments. Drug testing and analysis 2012.

Cone EJ, Tsadik A, Oyler J, Darwin WD. Cocaine Metabolism and Urinary Excretion After Different Routes of Administration. Therapeutic drug monitoring 1998;20:556-60.

EC. COMMISSION DECISION of 12 August 2002 implementing Council Directive 96/23/EC Concerning the performance of analytical methods and the interpretation of results 2002:8-36.

EMCDDA. Assessing illicit drugs in wastewater. Potential and limitations of a new monitoring approach. INSIGHTS 2008;9:1-106.

EMCDDA. The State of the Drugs Problem in Europe - Annual Report 2012. EMCDDA 2012:1-104.

Eriksen M, Mackay J, Ross H. The Tobacco Atlas. 4th ed. World Lung Foundation \& American Cancer Society; 2012.

EU. Attitudes of Europeans towards Tobacco - Eurobarometer 77.1 - Results for Portugal. 2012.

Gheorghe A, Nuijs A Van, Pecceu B, Bervoets L, Jorens PG, Blust R, Neels H, Covaci A. Analysis of cocaine and its principal metabolites in waste and surface water using solid-phase extraction and liquid chromatography - ion trap tandem mass spectrometry. Analytical and Bioanalytical Chemistry 2008:1309-19.

Goldstein RA, Deslauriers C, Pharm D, Burda AM, Pharm BS. Cocaine : History, Social Implications, and Toxicity - A Review. Disease a Month 2009;55:6-38.

Gorrod J Wahren J, ed. Nicotine and Related Alkaloids - Absorption, distribution, metabolism and excretion. SspringerScience+Business Media, BV; 1993.

Harris DS, Everhart ET, Mendelson J, Jones RT. The pharmacology of cocaethylene in humans following cocaine and ethanol administration. Drug and Alcohol Dependence 2003;72:169-82.

Haufroid V, Lison D. Urinary cotinine as a tobacco-smoke exposure index: a minireview. International archives of occupational and environmental health 1998;71:162-8.

Hukkanen J, lii PJ, Benowitz NL. Metabolism and Disposition Kinetics of Nicotine. Pharmacology 2005;57:79-115.

ICH. International Conference on Harmonization Tripartite Guideline(2005) ICH Topic Q2, Validation of Analytical Procedures: Text and Methodology, Geneva. 2005.

IDT. 2011 NATIONAL REPORT ( 2010 data ) TO THE EMCDDA by the Reitox National Focal Point " PORTUGAL" New Development Trends and in-depth information. 2011.

Irvine RJ, Kostakis C, Felgate PD, Jaehne EJ, Chen C, White JM. Population drug use in Australia: A wastewater analysis. Forensic science international 2011;210:69-73.

ISO. ISO 8466-1:1990 "Water Quality - Calibration and evaluation of analytical methods and estimation of performance characteristics". 1990.

Jeffcoat A, Perez-Reyes M, Hill J, Sadler B, Cook C. Cocaine disposition in humans after intravenous injection, nasal insufflation (snorting), or smoking. Drug Metabolism and Disposition 1989;17:153-9.

Karolak S, Nefau T, Bailly E, Solgadi A, Levi Y. Estimation of illicit drugs consumption by wastewater analysis in Paris area (France). Forensic science international 2010;200:153-60.

Kolbrich EA, Barnes AJ, Gorelick DA, Boyd SJ, Cone EJ, Huesfis MA. Major and minor metabolites of cocaine in human plasma following controlled subcutaneous cocaine administration. Journal of analytical toxicology 2006;30:501-10. 
Kolonen S, Tuomisto J, Puustinen P, Airaksinen MM. Smoking behavior in low-yield cigarette smokers and switchers in the natural environment. Pharmacology, biochemistry, and behavior 1991;40:177-80.

Metcalfe C, Tindale K, Li H, Rodayan A, Yargeau V. Illicit drugs in Canadian municipal wastewater and estimates of community drug use. Environmental pollution 2010;158:3179-85.

Murray E, Popek P, Schneider NG, Baer-weiss V, Gritz ER. Psychopharmacology Can Cigarette Size and Nicotine Content Influence Smoking and Puffing Rates ? Psychopharmacology 1978;58:303-6.

Nakazawa A, Shigeta M, Ozasa K. Smoking cigarettes of low nicotine yield does not reduce nicotine intake as expected: a study of nicotine dependency in Japanese males. BMC public health 2004;4:28.

Van Nuijs A, Abdellati K, Bervoets L, Blust R, Jorens PG, Neels H, Covaci A. The stability of illicit drugs and metabolites in wastewater, an important issue for sewage epidemiology? Journal of hazardous materials 2012;239-240:19-23.

Van Nuijs A, Castiglioni S, Tarcomnicu I, Postigo C, Lopez M, Alda D, Neels H, Zuccato E, Barcelo D, Covaci A. Illicit drug consumption estimations derived from wastewater analysis : A critical review. Science of the Total Environment 2011a;409:3564-77.

Van Nuijs A, Mougel J-F, Tarcomnicu I, Bervoets L, Blust R, Jorens PG, Neels H, Covaci A. Sewage epidemiology--a real-time approach to estimate the consumption of illicit drugs in Brussels, Belgium. Environment international 2011b;37:612-21.

Van Nuijs A, Pecceu B, Theunis L, Dubois N, Charlier C, Jorens PG, et al. Can cocaine use be evaluated through analysis of wastewater? A nation-wide approach conducted in Belgium. Addiction 2009a;104:734-41.

Van Nuijs A, Tarcomnicu I, Bervoets L, Blust R, Jorens PG, Neels H, Covaci A. Analysis of drugs of abuse in wastewater by hydrophilic interaction liquid chromatography-tandem mass spectrometry. Analytical and bioanalytical chemistry 2009b;395:819-28.

Ort C, Lawrence MG, Reungoat J, Mueller JF. Sampling for PPCPs in wastewater systems: comparison of different sampling modes and optimization strategies. Environmental science \& technology 2010;44:6289-96.

Ort C, Lawrence MG, Rieckermann J, Joss A. Sampling for pharmaceuticals and personal care products (PPCPs) and illicit drugs in wastewater systems: are your conclusions valid? A critical review. Environmental science \& technology 2010;44:6024-35.

Prinzleve M, Haasen C, Zurhold H, Matali JL, Bruguera E, Gerevich J, et al. Cocaine use in Europe - a multi-centre study: patterns of use in different groups. European addiction research 2004;10:147-55.

Reid MJ, Langford KH, Mørland J, Thomas K V. Quantitative assessment of time dependent drug-use trends by the analysis of drugs and related metabolites in raw sewage. Drug and alcohol dependence 2011;119:179-86.

RELACRE. Guia Relacre n ${ }^{\circ} 13$ - Validação de Métodos Internos de Ensaio em Análise Química, Relacre, Lisboa, 2000.2000.

Srinivasan K, Wang PP, Eley a T, White C a, Bartlett MG. Liquid chromatography--tandem mass spectrometry analysis of cocaine and its metabolites from blood, amniotic fluid, placental and fetal tissues: study of the metabolism and distribution of cocaine in pregnant rats. Journal of chromatography. B, Biomedical sciences and applications 2000;745:287-303.

Terzic S, Senta I, Ahel M. Illicit drugs in wastewater of the city of Zagreb (Croatia)--estimation of drug abuse in a transition country. Environmental pollution 2010;158:2686-93.

Thomas K V, Bijlsma L, Castiglioni S, Covaci A, Emke E, Grabic R, et al. Comparing illicit drug use in 19 European cities through sewage analysis. The Science of the total environment 2012;432:432-9.

Van Trijp J, Roos A. RIKILT-DLO, Model for the Calculation of Calibration Curves, RIKILT report 91.02, Wageningen, Netherlands. 1991. 
Umweltbundesamt Dessau-Rosslau. Umweltbundesamt, Dessau-Rosslau, Germany (1998) Available at http://www.umweltbundeswamt.de/survey/us98/nikotin.htm. 1998.

WHO. The Tobacco Atlas. 2002.

Zuccato E, Chiabrando C, Castiglioni S, Bagnati R, Fanelli R. Estimating community drug abuse by wastewater analysis. Environmental health perspectives 2008;116:1027-32.

Zuccato E, Chiabrando C, Castiglioni S, Calamari D, Bagnati R, Schiarea S, Fanelli R. Cocaine in surface waters : a new evidencebased tool to monitor community drug abuse. Environmental Health 2005;7:1-7.

Journal reference:

Analysis of cocaine and nicotine metabolites in wastewater by liquid chromatography-tandem mass spectrometry. Cross abuse index patterns on a major community.

Lopes A, Silva N, Bronze MR, Ferreira J, Morais J.

Sci Total Environ. 2014 Jul 15;487:673-80. doi: 10.1016/j.scitotenv.2013.10.042. Epub 2013 Nov 5. 